\title{
TINJAUAN KESELAMATAN LALU LINTAS TERHADAP GEOMETRIK JALAN RUAS TORAJA - PALOPO (STUDI KASUS STA. 379+170 - STA. 383+300)
}

\author{
Abdias Tandy Arrang ${ }^{1}$ \\ ${ }^{1}$ Dosen Program Studi Teknik Sipil Universitas Andi Djemma Palopo \\ dias_tandyarrang@yahoo.co.id
}

\begin{abstract}
ABSTRAK
Hasil perencanaan geometrik jalan harus memberikan keamanan pada pengendara.Desain tikungan yang baik akan mempertimbangkan kemanan kendaraan terhadap gaya sentrifugal dan tersedianya jarak pandang henti yang cukup untuk mengantisipasi keadaan yang tidak terduga dari lalu lintas atau hal lainnya dari arah yang berlawanan. Penelitian keamanan kendaraan terhadap gaya sentirfugal ini dilakukan dengan meninjau ulang hasil desain tikungan yang telah ada dengan menggunakan rumus hubungan $\mathrm{V}_{\mathrm{R}}, \mathrm{R}$ dan e. Sementara tinjauan keselamatan terhadap jarak pandang pada tikungan dianalisis dengan membandingakan jarak pandang yang ada di lapangan dengan rumus jarak pandang henti.Hasil tinjauan keselamatan lalu lintas terhadap gaya sentrifugal pada tikungan menunjukkan $75,41 \%$ tikungan tidak aman karena nilai $\mathrm{R}$ yang lebih besar dari $\mathrm{R}_{\min }$, sementara untuk tinjauan jarak pandang henti terdapat $13,11 \%$ tikungan yang tidak menyiapkan jarak pandang yang cukup untuk keamanan.
\end{abstract}

Kata kunci : Gaya Sentrifugal, Jarak Pandang Henti, Ruas Toraja - Palopo.

\section{PENDAHULUAN}

Pesatnya pembangunan menuntut tersedianya prasarana transportasi yang layak guna menunjang mobilitas masyarakat serta distribusi barang ke berbagai daerah.Jalan sebagai salah satu prasarana transportasi darat harus didesain tidak hanya untuk kemampuan menahan beban lalu lintas tapi juga harus mampu memberikan keamanan dan kenyamanan bagi pengendara yang melalui jalan tersebut. Ruas Toraja - Palopo merupakan jalan yang memiliki fungsi yang penting bagi pengembangan wilayah pada bagian utara Sulawesi Selatan. Hal ini disebabkan oleh karena ruas tersebut merupakan jalan yang menghubungkan wilayah Luwu Raya dan sekitarnya dengan Kabupaten Tana Toraja, Toraja Utara dan Enrekang.Kondisi terrain ruas ini sangat curam dengan kemiringan mencapai $20 \%$ bahkan lebih dan dipenuhi oleh tikungan yang tajam.

Pada Tahun 2013, Pemerintah melalui BP2JN Wilayah VI Makassar melakukan pekerjaan pengaspalan ulang jalan pada STA. $379+170$ - STA. $383+300$ ruas Jalan Toraja - Palopo.Penelitian ini bermaksud untuk meninjau hasil desain pekerjaan pengaspalan tersebut terhadap keselamatan terkait dengan geometrik jalan, khususnya keselamatan lalu lintas pada alinamen horisontal di setiap tikungan.

Tujuan penelitian ini adalah sebagai berikut: (1) Menganalisis apakah hasil desain tikungan yang dilakukan oleh konsultan perencana telah mempertimbangkan keselamatan pengendara terkait dengan gaya sentrifugal yang terjadi; (2) Menganalisis apakah jarak pandang henti yang ada pada setiap tikungan tersedia bagi pengendara untuk melakukan antisipasi jika ada halangan pada tikungan.

\section{METODE PENELITIAN}

Penelitian terhadap Gaya Sentrifugal Kendaraan pada Tikungan

Penelitian ini dilakukan dengan menganalisis ulang hasil desain tikungan terhadap keselamatan pengendara. Analisis dilakukan dengan membandingkan nilai 
jari-jari $(\mathrm{R})$, kemiringan superelevasi (e) terhadap kecepatan rencana $\left(\mathrm{V}_{\mathrm{R}}\right)$ pada hasil perencanaan dengan nilai $\mathrm{R}$, e, dan $\mathrm{V}_{\mathrm{R}}$ yang disarankan oleh Tata Cara Perencanaan Geometrik Jalan Antar Kabupaten (1997) untuk keselamatan kendaraan pada saat berada pada tikungan. Sumber data yang digunakan berupa data sekunder yaitu data yang diperoleh dari gambar hasil desain yang dilaksanakan oleh konsultan perencana. Menurut Tata Cara Perencanaan Geometrik Jalan Antar Kabupaten (1997) hubungan antara $V_{R}, R$ dan e pada sebuah tikungan adalah sebagai berikut :

Dimana :

$$
R_{\min }=\frac{V_{R}{ }^{2}}{127\left(e_{\max }+f\right)}
$$

$\mathrm{R}_{\min }=$ Jari-jari Minimum (m)

$\mathrm{V}_{\mathrm{R}}=$ Kecepatan Rencana $(\mathrm{km} / \mathrm{jam})$

$\mathrm{e}_{\max }=$ Superelevasi maksimum $(\%)$

$\mathrm{f} \quad=$ Koefisien gesek, untuk aspal perkerasan aspal $\mathrm{f}=0,14-0,24$

Penelitian terhadap Jarak Pandang Henti

Penelitian jarak pandang dilakukan dengan membandingkan jarak pandang yang tersedia pada setiap tikungan dengan jarak pandang henti yang disarankan untuk keselamatan oleh Tata Cara Perencanaan Geometrik Jalan Antar Kabupaten 1997.Untuk penelitian jarak pandang ini, data yang digunakan adalah data primer di mana peneliti melakukan pengukuran langsung terhadap jarak pandang yang tersedia pada lapangan.

Menurut Tata Cara Perencanaan Geometrik Jalan Antar Kabupaten (1997) jarak minimum yang dibutuhkan oleh seorang pengendara sesaat setelah melihat halangan adalah sebagai berikut :

Dimana :

$$
J_{h}=\frac{V_{R}}{3,6} T+\frac{\left(\frac{V_{R}}{3,6}\right)^{2}}{2 g f}
$$

$\mathrm{J}_{\mathrm{h}} \quad=\quad$ Jarak pandang henti (m)

$\mathrm{T}=$ Waktu Tanggap, ditetapkan 2,5 detik

$\mathrm{g}=$ Percepatan gravitasi, $9,8 \mathrm{~m} / \mathrm{det}^{2}$

$\mathrm{V}_{\mathrm{R}}=$ Kecepatan Rencana $(\mathrm{km} / \mathrm{jam})$

$\mathrm{fp} \quad=$ Koefisien gesek memanjang perkerasan aspal, untuk aspal perkerasan aspal ditetapkan $\mathrm{f}=0,35-0,55$

\section{HASIL DAN PEMBAHASAN}

Analisis Keamanan Kendaraan terhadap Gaya Sentrifugal Kendaraan pada Tikungan

Sepanjang ruas jalan yang menjadi lokasi penelitian (STA. 379+170 - STA. $383+300)$ terdapat 61 tikungan. Data perencanaan yaitu : kecepatan rencana $\left(V_{R}\right)$, superelevasi (e) dan jari-jari (R) pada tikungan dianalis keamanannya dengan menggunakan persamaan (1). Pada penelitian ini digunakan nilai koefesien gesek (f) sebesar 1,65. Hasil analisis menunjukkan bahwa dari 61 tikungan yang ada, hanya15 tikungan $(24,59 \%)$ dengan nilai $\mathrm{R}$ yang lebih besar dari nilai $\mathrm{R}_{\min }$ seperti yang disyaratkan oleh persamaan (1). Sementara 46 tikungan $(75,41 \%)$ tidak memenuhi syarat $\mathrm{R}_{\mathrm{min}}$. Tikungan yang memenuhi syarat tersebut adalah : PI 19 , PI 21, PI 29, PI 34, PI 36, PI 39, PI 40, PI 41, PI 44, PI 46, PI 49, PI 50,PI 52, PI 53, dan PI 61. Hasil 
analisis data dapat dilihat pada Tabel 1 dengan membandingkan kolom (4) dan kolom (5).

Sementara usaha untuk meningkatkan keamanan pengendara pada 47 tikungan yang memiliki jari-jari $(\mathrm{R})$ melebihi $\mathrm{R}_{\text {min }}$ dapat dilakukan dengan memperbesar sudut superelevasi $\left(\mathrm{e}_{\max }\right)$. Namun menurut AAHSTO dalam Hendarsin (2000) nilai superlevasi $\left(\mathrm{e}_{\max }\right)$ terbesar untuk perencanaan adalah $10 \%$. Hasil analisis nilai $\mathrm{e}_{\max }$ yang disarankan untuk 47 tikungan tersebut dapat dilihat pada Tabel 1 kolom (6).Pada Kolom (6) terlihat bahwa ada 23 tikungan yang hasil analisisnya menunjukkan nilai $\mathrm{e}_{\max }$ yang lebih besar dari $10 \%$, sehingga tidak memungkinkan untuk melakukan penambahan sudut superelevasi. Cara lain yang dapat dilakukan untuk memberikan keamanan bagi pengendara pada tikungan yang nilai $\mathrm{R}$ nya tidak memenuhi syaratadalah dengan menurunkan kecepatan.Hasil analisis untuk nilai $\mathrm{V}_{\mathrm{R}} \mathrm{yang}$ aman bagi pengendara dapat dilihat pada Tabel 1 kolom (7). Nilai $\mathrm{V}_{\mathrm{R}} \mathrm{yang}$ terkecil setelah diturunkan adalah 17 km/jam yaitu pada tikungan PI 31.

Tabel 1. Hasil Analisis Keamanan terhadap Gaya Sentrifugal pada Tikungan

\begin{tabular}{|c|c|c|c|c|c|c|c|}
\hline \multirow{2}{*}{ PI } & \multicolumn{3}{|c|}{$\begin{array}{l}\text { Data dari Hasil Desain } \\
\text { Konsultan Perencana }\end{array}$} & \multicolumn{3}{|c|}{ Hasil Analisis } & \multirow{2}{*}{ Keterangan } \\
\hline & $\begin{array}{l}\mathrm{V}_{\mathrm{R}} \\
(\mathrm{m})\end{array}$ & $\begin{array}{l}\mathrm{e}_{\max } \\
(\%)\end{array}$ & $\begin{array}{c}\mathrm{R} \\
(\mathrm{m})\end{array}$ & $\begin{array}{l}\mathrm{R}_{\min } \\
(\mathrm{m})\end{array}$ & $\begin{array}{l}\mathrm{e}_{\max } \\
(\%)\end{array}$ & $\begin{array}{l}\mathrm{V}_{\mathrm{R}} \\
(\mathrm{m})\end{array}$ & \\
\hline (1) & (2) & (3) & (4) & $(5)$ & $(6)$ & (7) & (8) \\
\hline 1 & 40 & 3,8 & 30 & 62 & 25,5 & 28 & $\mathrm{e}_{\max }>10 \%$ \\
\hline 2 & 30 & 5,2 & 20 & 33 & 18,9 & 23 & $\mathrm{e}_{\max >10} \%$ \\
\hline 3 & 40 & 4,8 & 50 & 59 & 8,7 & 37 & \\
\hline 4 & 40 & 4,7 & 50 & 59 & 8,7 & 37 & \\
\hline 5 & 30 & 5,4 & 30 & 32 & 7,1 & 29 & \\
\hline 6 & 40 & 3,5 & 60 & 63 & 4,5 & 39 & \\
\hline 7 & 40 & 3,5 & 40 & 63 & 15,0 & 32 & $\mathrm{e}_{\max }>10 \%$ \\
\hline 8 & 30 & 3,5 & 15 & 35 & 30,7 & 20 & $\mathrm{e}_{\max }>10 \%$ \\
\hline 9 & 30 & 5,8 & 20 & 32 & 18,9 & 24 & $\mathrm{e}_{\max }>10 \%$ \\
\hline 10 & 30 & 5,9 & 30 & 32 & 7,1 & 29 & \\
\hline 11 & 30 & 4,0 & 30 & 35 & 7,1 & 28 & \\
\hline 12 & 30 & 4,5 & 16 & 34 & 27,8 & 21 & $\mathrm{e}_{\max }>10 \%$ \\
\hline 13 & 30 & 4,6 & 30 & 34 & 7,1 & 28 & \\
\hline 14 & 30 & 5,8 & 30 & 32 & 7,1 & 29 & \\
\hline 15 & 40 & 4,9 & 40 & 59 & 15,0 & 33 & $\mathrm{e}_{\max }>10 \%$ \\
\hline 16 & 50 & 3,6 & 100 & 98 & 3,2 & 51 & \\
\hline 17 & 40 & 3,1 & 40 & 64 & 15,0 & 32 & $\mathrm{e}_{\max }>10 \%$ \\
\hline 18 & 30 & 4,7 & 15 & 33 & 30,7 & 20 & $\mathrm{e}_{\max }>10 \%$ \\
\hline 19 & 50 & 6,4 & 200 & 86 & - & - & \\
\hline 20 & 30 & 3,3 & 18 & 36 & 22,9 & 21 & $\mathrm{e}_{\max }>10 \%$ \\
\hline 21 & 40 & 5,1 & 70 & 58 & 1,5 & - & \\
\hline 22 & 30 & 3,3 & 35 & 36 & 3,7 & 30 & \\
\hline 23 & 30 & 5,3 & 20 & 33 & 18,9 & 24 & $\mathrm{e}_{\max }>10 \%$ \\
\hline 24 & 30 & 6,7 & 30 & 31 & 7,1 & 30 & \\
\hline 25 & 30 & 5,4 & 40 & 32 & 1,2 & 33 & \\
\hline 26 & 40 & 5,4 & 40 & 58 & 15,0 & 33 & $\mathrm{e}_{\max }>10 \%$ \\
\hline 27 & 30 & 4,4 & 40 & 34 & 1,2 & 33 & \\
\hline 28 & 30 & 5,3 & 40 & 33 & 1,2 & 33 & \\
\hline 29 & 30 & 5,3 & 60 & 33 & - & - & \\
\hline 30 & 30 & 4,7 & 20 & 33 & 18,9 & 23 & $\mathrm{e}_{\max }>10 \%$ \\
\hline $31^{\prime}$ & 30 & 5,1 & 11 & 33 & 47,9 & 17 & $\mathrm{e}_{\max >10} \%$ \\
\hline 32 & 30 & 6,8 & 25 & 30 & 11,8 & 27 & $\mathrm{e}_{\max }>10 \%$ \\
\hline 33 & 30 & 6,4 & 40 & 31 & 1,2 & 34 & \\
\hline
\end{tabular}




\begin{tabular}{|l|l|l|c|c|c|c|c|}
\hline 34 & 40 & 6,1 & 130 & 56 & - & - & \\
\hline 35 & 30 & 3,6 & 21 & 35 & 17,2 & 23 & $\mathrm{e}_{\max }>10 \%$ \\
\hline 36 & 40 & 6,5 & 150 & 55 & - & - & \\
\hline 37 & 30 & 3,3 & 25 & 36 & 11,8 & 25 & $\mathrm{e}_{\max }>10 \%$ \\
\hline 38 & 30 & 6,4 & 25 & 31 & 11,8 & 27 & \\
\hline 39 & 30 & 6,4 & 50 & 31 & - & - & \\
\hline 40 & 30 & 6,4 & 35 & 31 & 3,7 & 32 & \\
\hline 41 & 30 & 6,2 & 30 & 31 & 7,1 & 29 & \\
\hline 42 & 30 & 6,3 & 25 & 31 & 11,8 & 27 & $\mathrm{e}_{\max }>10 \%$ \\
\hline 43 & 30 & 6,4 & 80 & 31 & - & 48 & \\
\hline 44 & 30 & 5,1 & 40 & 33 & 1,2 & 33 & \\
\hline 45 & 40 & 6,5 & 80 & 55 & - & - & \\
\hline 46 & 30 & 5,1 & 40 & 33 & 1,2 & - & \\
\hline 47 & 50 & 5,1 & 315 & 91 & - & 93 & \\
\hline 48 & 30 & 3,1 & 33 & 36 & 5,0 & 29 & \\
\hline 49 & 50 & 3,1 & 300 & 100 & - & - & \\
\hline 50 & 50 & 3,3 & 200 & 99 & - & - & \\
\hline 51 & 30 & 4,1 & 26 & 34 & 10,8 & 26 & $\mathrm{e}_{\max }>10 \%$ \\
\hline 52 & 40 & 6,4 & 120 & 55 & - & - & \\
\hline 53 & 30 & 4,1 & 60 & 34 & - & - & \\
\hline 54 & 30 & 6,1 & 35 & 31 & 3,7 & 32 & \\
\hline 55 & 30 & 6,2 & 20 & 31 & 18,9 & 24 & $\mathrm{e}_{\max }>10 \%$ \\
\hline 56 & 30 & 6,6 & 25 & 31 & 11,8 & 27 & $\mathrm{e}_{\max }>10 \%$ \\
\hline 57 & 30 & 6,4 & 30 & 31 & 7,1 & 30 & \\
\hline 58 & 40 & 6,3 & 30 & 55 & 25,5 & 29 & $\mathrm{e}_{\max }>10 \%$ \\
\hline 59 & 30 & 6,3 & 30 & 31 & 7,1 & 29 & \\
\hline 60 & 30 & 8,8 & 20 & 28 & 18,9 & 25 & $\mathrm{e}_{\max }>10 \%$ \\
\hline 61 & 40 & 6,5 & 90 & 55 & - & - & \\
\hline & & & & & & & \\
\hline
\end{tabular}

Analisis Keamanan Kendaraan terhadap Jarak Pandang pada Tikungan

Untuk mengetahui jarak pandang yang tersedia pada masing-masing tikungan dilakukan dengan melakukan pengukuran langsung di lokasi penelitian.Hasil pengukuran lapangan dibandingkan dengan nilai $\mathbf{J}_{\mathrm{h}}$ yang disarankan oleh persamaan (2). Pada penelitian ini digunakan koefisien gesek memanjang perkerasan aspal $\left(\mathrm{f}_{\mathrm{p}}\right)=$ 0,45 . Hasil analisis data seperti yang ditunjukkan pada Tabel 2terlihat bahwa dari 61 tikungan yang ada, terdapat8 tikungan $(13,11 \%)$ memiliki jarak pandang yanglebih besar dari jarak pandang henti $\left(\mathrm{J}_{\mathrm{h}}\right)$ yang disarankan oleh persamaan (2),dengan demikian tikungan tersebut tidak aman bagi pengendara. Tikungan yang tidak aman adalah PI 6, PI 16, PI 19, PI 45, PI 47, PI 49, PI 50 dan PI 52. Sementara 53 tikungan lainnya $(86,89 \%)$ memiliki jarak pandang henti yang cukup.

Untuk keamanan pengendara dalam mengantisipasi hal-hal yang tidak terduga akibat kendaraan dari arah berlawanan pada tikungan, maka pada 8 tikungan yang tidak aman disarankan agar menurunkan kecepatan $\left(\mathrm{V}_{\mathrm{R}}\right)$ seperti yang

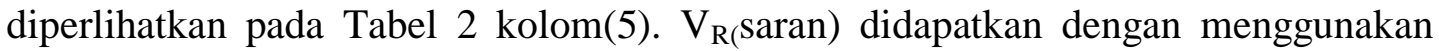
persamaan (2) dimana nilai Jh menggunakan nilai Jh lapangan.Kecepatan terendah setelah diturunkan untuk keamanan jarak pandang adalah $35 \mathrm{~km} / \mathrm{jam}$ yaitu pada tikungan PI 16. Untuk memperluas jarak pandang pada tikungan juga dapat dilakukan dengan memasang cermin tikungan pada kedelapan tikungan yang tidak aman tersebut di atas.Pemasangan cermin tikungan dapat merefleksikan bayangan kendaraan dari arah berlawanan meskipun jarak pandang henti tidak cukup tersedia. 
Tabel 2. Hasil Analisis Keamanan terhadap Jarak Pandang Henti

\begin{tabular}{|c|c|c|c|c|c|}
\hline PI & $\begin{array}{c}\mathrm{V}_{\mathrm{R}}(\text { Desain }) \\
(\mathrm{km} / \mathrm{jam})\end{array}$ & $\begin{array}{l}\text { Jh Lap. } \\
\text { (m) }\end{array}$ & $\begin{array}{c}\text { Jh Analisis } \\
(\mathrm{m})\end{array}$ & $\begin{array}{l}\mathrm{V}_{\mathrm{R}}(\mathrm{Saran}) \\
(\mathrm{km} / \mathrm{jam})\end{array}$ & Keterangan \\
\hline (1) & $(2)$ & (3) & $(4)$ & (5) & $(6)$ \\
\hline 1 & 40 & 42 & 42 & - & Terpenuhi \\
\hline 2 & 30 & 37 & 29 & - & Terpenuhi \\
\hline 3 & 40 & TTH*) & 42 & - & Terpenuhi \\
\hline 4 & 40 & 42 & 42 & - & Terpenuhi \\
\hline 5 & 30 & 34 & 29 & - & Terpenuhi \\
\hline 6 & 40 & 38 & 42 & 37 & Tidak Terpenuhi \\
\hline 7 & 40 & 46 & 42 & - & Terpenuhi \\
\hline 8 & 30 & 42 & 29 & - & Terpenuhi \\
\hline 9 & 30 & 35 & 29 & - & Terpenuhi \\
\hline 10 & 30 & 34 & 29 & - & Terpenuhi \\
\hline 11 & 30 & 36 & 29 & - & Terpenuhi \\
\hline 12 & 30 & 35 & 29 & - & Terpenuhi \\
\hline 13 & 30 & 37 & 29 & - & Terpenuhi \\
\hline 14 & 30 & 40 & 29 & - & Terpenuhi \\
\hline 15 & 40 & 47 & 42 & - & Terpenuhi \\
\hline 16 & 50 & 35 & 57 & 35 & Tidak Terpenuhi \\
\hline 17 & 40 & TTH*) & 42 & - & Terpenuhi \\
\hline 18 & 30 & TTH*) & 29 & - & Terpenuhi \\
\hline 19 & 50 & 42 & 57 & 40 & Tidak Terpenuhi \\
\hline 20 & 30 & 45 & 29 & - & Terpenuhi \\
\hline 21 & 40 & TTH*) & 42 & - & Terpenuhi \\
\hline 22 & 30 & TTH*) & 29 & - & Terpenuhi \\
\hline 23 & 30 & 45 & 29 & - & Terpenuhi \\
\hline 24 & 30 & 49 & 29 & - & Terpenuhi \\
\hline 25 & 30 & TTH*) & 29 & - & Terpenuhi \\
\hline 26 & 40 & 48 & 42 & - & Terpenuhi \\
\hline 27 & 30 & 36 & 29 & - & Terpenuhi \\
\hline 28 & 30 & 49 & 29 & - & Terpenuhi \\
\hline 29 & 30 & 45 & 29 & - & Terpenuhi \\
\hline 30 & 30 & 35 & 29 & - & Terpenuhi \\
\hline $31^{\prime}$ & 30 & 42 & 29 & - & Terpenuhi \\
\hline 32 & 30 & 40 & 29 & - & Terpenuhi \\
\hline 33 & 30 & TTH*) & 29 & - & Terpenuhi \\
\hline 34 & 40 & TTH*) & 42 & - & Terpenuhi \\
\hline 35 & 30 & 49 & 29 & - & Terpenuhi \\
\hline 36 & 40 & 42 & 42 & - & Terpenuhi \\
\hline 37 & 30 & 37 & 29 & - & Terpenuhi \\
\hline 38 & 30 & 43 & 29 & - & Terpenuhi \\
\hline 39 & 30 & 43 & 29 & - & Terpenuhi \\
\hline 40 & 30 & 39 & 29 & - & Terpenuhi \\
\hline 41 & 30 & TTH*) & 29 & - & Terpenuhi \\
\hline 42 & 30 & 36 & 29 & - & Terpenuhi \\
\hline 43 & 30 & 32 & 29 & - & Terpenuhi \\
\hline 44 & 30 & TTH*) & 29 & - & Terpenuhi \\
\hline 45 & 40 & 38 & 42 & 37 & Tidak Terpenuhi \\
\hline 46 & 30 & 35 & 29 & - & Terpenuhi \\
\hline 47 & 50 & 40 & 49 & 39 & Tidak Terpenuhi \\
\hline 48 & 30 & 43 & 29 & - & Terpenuhi \\
\hline 49 & 50 & 46 & 57 & 43 & Tidak Terpenuhi \\
\hline 50 & 50 & 33 & 57 & - & Tidak Terpenuhi \\
\hline 51 & 30 & 48 & 29 & - & Terpenuhi \\
\hline
\end{tabular}




\begin{tabular}{|l|l|c|c|c|c|}
\hline 52 & 40 & 40 & 42 & 39 & Tidak Terpenuhi \\
\hline 53 & 30 & 41 & 29 & - & Terpenuhi \\
\hline 54 & 30 & TTH $\left.^{*}\right)$ & 29 & - & Terpenuhi \\
\hline 55 & 30 & 47 & 29 & - & Terpenuhi \\
\hline 56 & 30 & 46 & 29 & - & Terpenuhi \\
\hline 57 & 30 & 50 & 29 & - & Terpenuhi \\
\hline 58 & 40 & 54 & 42 & - & Terpenuhi \\
\hline 59 & 30 & 53 & 29 & - & Terpenuhi \\
\hline 60 & 30 & 38 & 29 & - & Terpenuhi \\
\hline 61 & 40 & 46 & 42 & - & Terpenuhi \\
\hline
\end{tabular}

TTH*) : Jarak Pandang Tersedia (Tidak Terhalang)

\section{KESIMPULAN}

Hasil tinjauan keselamatan lalu lintas terhadap 61 tikungan yang diteliti dapat dismpulkan sebagai berikut:

1) Terdapat 15 tikungan $(24,59 \%)$ yang memenuhi syarat keamanan terhadap gaya sentrifugal kendaraan pada tikungan, sementara sisanya 46 tikungan $(75,41 \%)$ tidak memenuhi syarat keamanan. Untuk itu, pada tikungan yang tidak aman diusulkan untuk menaikkan kemiringan superelevasi $\left(\mathrm{e}_{\max }\right)$.Namun demikian, masih terdapat 23 tikungan yang tidak memungkinkan untuk menambah $\mathrm{e}_{\max }$, karena melebihi $10 \%$. Saran lain adalah dengan menurunkan kecepatan, dan hasil analisis menunjukkan penurunan kecepatan yang paling rendah pada tikungan PI 31 yaitu sebesar $17 \mathrm{~km} / \mathrm{jam}$.

2) Terdapat 53 tikungan $(86,89 \%)$ yang memenuhi syarat ketersediaan jarak pandang, sementara 8 tikungan $(13,11 \%)$ tidak memenuhi syarat (tidak aman). Untuk keamanan pengendara, disarankan untuk menurunkan kecepatan. Penurunan kecepatan yang paling rendah sebesar 35 km/jam pada tikungan PI 16. Saran lain yaitu dengan memasang cermin tikungan untuk memperluas jarak pandang pada tikungan.

\section{DAFTAR PUSTAKA}

Departemen Pekerjaan Umum Direktorat Jenderal Bina Marga, Jalan - No. 038/T/BM/1997, Jakarta.

Fachrurrozy, 2007, BahanAjar Mata Kuliah Kesematan Lalu Lintas, Magister Sistem dan Teknik Transportasi Universitas Gadjah Mada, Yogyakarta.

Hendarsin, Shirley L., 2000, Penuntun Praktis Perencanaan Teknik Jalan Raya, Politeknik Negeri Bandung - Jurusan Teknik Sipil, Bandung.

TMS Consultancy, 2001, Practical Road Safety Auditing, Thomas Telford Publishing, London. 